\title{
Personality and Job Stress: A Comparison of Direct Effects on Parenting
}

\author{
Angel Blanch and Anton Aluja \\ Universitat de Lleida (Spain)
}

\begin{abstract}
The impact of personality and job characteristics on parental rearing styles was compared in 353 employees. Hypotheses concerning the relationships between personality and job variables were formulated in accordance with findings in past research and the Belsky's model (1984). Structural equation nested models showed that Aggression-hostility, Sociability and job Demand were predictive of Rejection and Emotional Warmth parenting styles, providing support for some of the hypothesized relationships. The findings suggest a well-balanced association of personality variables with both parenting styles: Aggression-Hostility was positively related to Rejection and negatively to Emotional Warmth, whereas Sociability was positively related to Emotional Warmth and negatively related to Rejection. Personality dimensions explained a higher amount of variance in observed parenting styles. However, a model that considered both, personality and job dimensions as antecedent variables of parenting was the best representation of observed data, as both systems play a role in the prediction of parenting behavior.
\end{abstract}

Keywords: personality, job stress, parenting.

El impacto de la personalidad y las características del trabajo sobre los estilos educativos paternos se comparó en 353 trabajadores. Se formularon hipótesis sobre las relaciones entre variables de personalidad y laborales de acuerdo con los resultados de investigaciones anteriores y el modelo de Belsky (1984). La evaluación de una serie de modelos de ecuaciones estructurales anidados, mostró que la Agresión - hostilidad, la Sociabilidad, y las demandas de trabajo eran predictivas de estilos educativos de Rechazo y Calidez Emocional, apoyando algunas de las relaciones hipotetizadas. Los resultados sugieren una asociación equilibrada de las variables de personalidad con ambos tipos de estilos educativos: Agresión - hostilidad se asoció positivamente con Rechazo y negativamente con Calidez Emocional, mientras que Sociabilidad se asoció positivamente con Calidez Emocional y negativamente con Rechazo. Las dimensiones de personalidad explicaron una mayor proporción de varianza en los estilos educativos. En cualquier caso, un modelo incluyendo tanto variables de personalidad como laborales como antecedentes de los estilos educativos, mostró la mejor representación de los datos observados, ya que ambos sistemas parecen jugar un papel importante en la predicción de conductas de educación parental.

Palabras clave: personalidad, estrés laboral, estilos educativos.

Correspondence concerning this article should be addressed to Angel Blanch. Departamento de Pedagogía y Psicología, Facultad de Ciencias de la Educación. Universitat de Lleida. Avda de l'Estudi General, 4. 25001 Lleida (Spain). Phone: +34-973706529. E-mail: ablanch@pip.udl.cat 
The increasing amount of dual-income couples and the new forms of labor relations have stimulated the study of the influences between the work and family domains in marital functioning (Hughes \& Galinsky, 1994; Repetti, 1989; Story $\&$ Repetti, 2006), or adjustment to parenthood with newborn or very young children (Belsky, Gilstrap, \& Rovine, 1984; Costigan, Cox, \& Cauce, 2003; Jarvis \& Creasey, 1991). Besides, job stress antecedents and outcomes have been consistently associated with family-related variables: work - family conflict (Allen, Herst, Bruck, \& Sutton, 2000; Blanch \& Aluja, 2009), family interactions (Barnett, Gareis, \& Brennan, 1999; Repetti \& Wood, 1997), and stress in the marriage (Jayaratne, Chess, \& Kunkel, 1986). However, there is a paucity of research about specific work antecedents related with parenting, despite the large body of evidence showing that parental behaviors are indeed robust precursors of general child well-being and socialization processes (Baumrind, 1971; Enns, Cox, \& Larsen, 2000; García, Aluja, \& del Barrio, 2006; Goodman \& Gotlib, 1999; Hoffman, 1975; Kacynski, Lindahl, Malik, \& Laurenceau, 2006; Pedersen, 1994; Zemore \& Rinholm, 1989). For instance, it has been suggested that an excessive control and discipline is likely to elicit hostility and socialization deficits in children (Houston \& Vavak, 1991), whereas sensitive and supportive parents seem to contribute positively to a greater competence and resourcefulness of schoolchildren (National Institute of Child Health and Human Development Early Child Care Research Network, 2004).

While the influence of parenting on child well-being and socialization is well-established, there is a need of further studies attempting to explain parenting from personality and work antecedents to better understand the work and family interface in regard to parenting. Therefore, we compared the relative influence of individual and contextual determinants on different parenting styles.

\section{Individual and contextual determinants of parenting}

Theoretical models attempting to explain children behavior from parenting practices indicate that parenting is determined from three main subsystems: the child individual characteristics, the contextual characteristics, and the parent's psychological resources (Abidin, 1992; Belsky, 1984). Each of these subsystems would be regulated by a degree of stress or support determining in turn a certain level of parental functioning, with parenting being more adequate with the factors in each subsystem functioning in the support mode, and less adequate when functioning in the stress mode (Belsky, 1984; see Figure 1).

The influence of personal dispositions on parenting have been mostly approached in regard to psychological disorders (Baumrind, 1971) neglecting the analysis of 'normal' personality traits such as those identified by the Big Five (i.e., Extraversion, Agreeableness, Conscientiousness, Neuroticism, and Openness; McCrae \& Costa, 1999). Nevertheless, it has been suggested that personality might influence parenting through two main

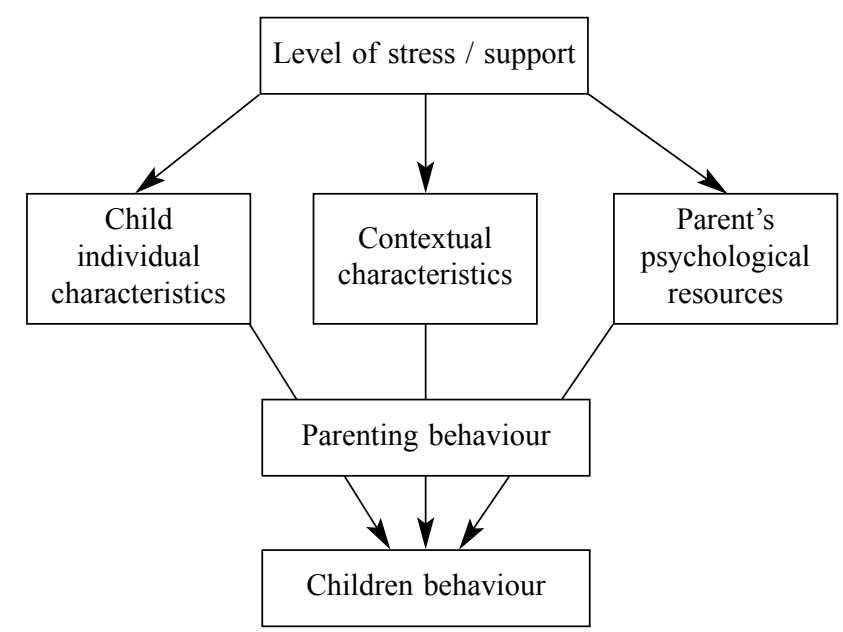

Figure 1. Contextual and individual determinants of parenting.

paths: a) mood: Extraversion and Neuroticism would foster positive and negative emotional experiences, respectively; and b) daily hassles: parents more exposed to daily hassles would be more likely to be irritable and less supportive in their interactions with children (Patterson, 1983; Tellegen, 1985). Thus, healthier individual dispositions derived from either pathway might exert optimal influences on parenting and on child development, as suggested by empirical works (Belsky, Crnic, \& Woodworth, 1995; Clark, Kochanska, \& Ready, 2000; Kochanska, Aksan, Penney, \& Boldt, 2007). For instance, flexible and warmth parenting has been positively related to extraversion, agreeableness, conscientiousness and openness to experience, and negatively related to neuroticism, whereas punitive and controlling parenting has been positively related to conscientiousness, and negatively related to openness to experience (Peterson, Smirles, \& Wenworth, 1997). The moderating effect of parent's personality has also been recently addressed, suggesting that high levels of extraversion and socialization for mothers, and low levels of neuroticism and high levels of socialization for fathers, buffered the negative impact of demographic risk on the quality of parenting (Kochanska et al., 2007).

In regard to the contextual determinants of parenting, three main sources of stress and/or support have been delineated: marital relationships, social network, and work. This model might supply a useful framework to analyze parenting in regard to the work environment which has been rather overlooked in this line of research. There is however supportive evidence indicating a consistent association of work variables with parenting (Crouter \& Bumpus, 2001; Kinnunen, Gerris, \& Vermulst, 1996). Long working hours have been associated to higher levels of maternal role strain, whereas higher schedule flexibility has been related to lower levels of role strain (Morris $\&$ Coley, 2004). Besides, a high degree of work-load has been consistently related with behavioral and emotional withdrawal in interactions with children at home (Repetti, 1994), whereas negative social experiences at work such as low levels of social support have been significantly related 
with expressions of anger, greater use of discipline, decreasing positive parenting and increasing negative parenting (Costigan et al., 2003; Repetti, 1994).

\section{The present study}

In accordance with Belsky's model (1984), personality dimensions and job characteristics are key variables in regard to parenting behavior. However, and to our knowledge, no research to date has explicitly compared the direct effects of personality dispositions and work situational variables on parenting styles. The Belsky's model (1984) suggests that mediation effects for either personality or work variables would be likely. However, and given the paucity of research tackling personality and job variables in a single model to predict parenting, we approach this issue with a simpler direct effects model. Therefore, the present study was designed to compare the direct effects of personality and job variables on parental rearing styles rather than focusing on more complex mediation and/or moderation models.

We used the alternative personality big five model including: impulsive sensation seeking, characterized by the need of seeking new experiences; neuroticism-anxiety, which defines low emotional stability and distress; aggressionhostility, depicting an antagonistic attitude towards others; activity, which reflects high levels of energy and liveliness; and sociability, describing a will to be with others (Zuckerman, 2005). Factor analyses demonstrating the relationships between the big five and the alternative big five personality models have shown that neuroticism - anxiety loaded positively in the neuroticism factor, aggression - hostility loaded negatively in the agreeableness factor, and activity and sociability loaded positively in the extraversion factor (Zuckerman, Kuhlman, Joireman, Teta, \& Kraft, 1993). Therefore we hypothesized that (a) Neuroticism and Aggression-Hostility would be positively related to rejection and that (b) Sociability would be positively related to affectionate parenting (Belsky et al., 1995; Clark et al., 2000; Peterson et al., 1997).

In regard to job situational variables previously investigated in the literature (Costigan et al., 2003; Repetti, 1994), it was hypothesized that 3) Working conditions such as high work-load, and low social support at work would be positively related to rejection parenting.

Finally and in accordance with the Belsky's model (1984), we hypothesized that 4) A model considering the influence of both, work environment and personality variables would provide the best representation of observed data.

\section{Method}

\section{Participants and procedure}

A sample of 353 participants took part in the study, 152 male and 200 female, and an individual not reporting gender.
Mean participants' age was 44.7 years $(S D=7.33)$, they were married or co-habiting, and had one or more schoolage children at home, with a mean age of children living at home of 15 years $(S D=7.83)$. Over $45 \%$ of the sample held a university degree, $22 \%$ had completed professional training, and the rest had completed secondary education studies. Participants worked at Spanish public and private organizations, at administrative, management, technical and educational job posts, with a working time schedule of 38 hours per week and a mean job experience of 15.8 years $(S D=9.09)$. Eight-hundred questionnaires were delivered to the employees, after formal authorization to carry out the study was obtained and participants had been informed through the internal communication channels of organizations. Only 421 of the questionnaires were returned, about $52 \%$ of the questionnaires initially handed out, although only 353 were selected for the present study, considering the criterion of having school-age children at home.

\section{Instruments}

Parenting styles ratings were obtained from the Rejection and Emotional Warmth subscales of the EMBU (Egna Minnen Beträffande Uppfostran; Arrindell et al., 2005; Castro, de Pablo, Gómez, Arrindell, \& Toro, 1997): (a) Rejection (7 items: You have been sour or angry with your children without letting them know the cause), measures a trend to physical punishment, and hostility and lack of respect towards children ( $\alpha=.67)$; (b) Emotional warmth (6 items: You think that there has been warmth and tenderness between you and your children), taps warmth and loving attitudes, intellectual stimulation and respect towards children $(\alpha=$ $.70)$. Parents were asked to respond in regard to the general attitude towards their children at home on a 4 - point frequency scale, from 4 (yes, always) to 1 (no, never).

Personality dimensions were assessed with a 69-item version of the Zuckerman-Kuhlman Personality Questionnaire (ZKPQ-III-R; Aluja, García, \& García, 2003): (a) Neuroticism-Anxiety (18 items: I am easily frightened): Describes lack of emotional stability, distress, uneasiness, and lack of self-confidence ( $\alpha=.81)$; (b) Aggression-Hostility (13 items: I almost never feel like I would like to hit someone): Reflects a predisposition to express verbal aggression, coarse and antisocial behaviors $(\alpha=.76)$; (c) Sociability (13 items: I spend as much time with my friends as I can): These items describe a preference for being with others, as opposed to solitary activities $(\alpha=.73)$. The scales were answered on a true - false format. Reliability alpha internal consistencies $(\alpha)$ were acceptable and equivalent to those reported in the original studies.

Two well established job characteristics in the job stress literature were evaluated with the Job Content Questionnaire (Karasek, 1985; Karasek et al., 1998): (a) Job demand (9 items: My job requires me to work very hard): measures the degree of psychological work-load $(\alpha=.70)$; (b) Job 
support (11 items: The people I work with are friendly): taps useful social interaction at the job place $(\alpha=.87)$. All items were answered on a four-point Likert type scale, from 1 (strongly disagree) to 4 (strongly agree). This instrument was back-translated and approved by the original author.

\section{Statistical analyses}

Hypotheses were tested with structural equation modeling (Bollen, 1989). A model was specified with endogenous latent variables representing each parental style tapped by the observed items. Personality and work variables were included as observed exogenous predictors of parenting (see Figure 2). Correlations were specified for exogenous variables within domain, i.e., personality and job variables, and between the disturbances of endogenous latent variables. Three nested models were estimated: (a) Personality model: constraining the job variables parameters to 0 ; (b) Job model: constraining the personality variables parameters to 0; and (c) Mixed model: all parameters were set free. Chi-square difference tests $\left(\Delta \chi^{2}\right)$ were used to evaluate the best fitting model. A significant chi-square difference indicated that the model with fewer degrees of freedom was a better representation of observed data. Additional fit indices, Goodness-of-Fit Index (GFI), Comparative Fit Index (CFI), Tucker-Lewis Index (TLI), and Root Mean Square Error of Approximation (RMSEA), with values higher than .90 for GFI, CFI, and TLI, and lower than .08 for RMSEA being indicative of a good fit to data (Browne \& Cudeck, 1993). The variance-covariance matrix was used as input data, and parameters were estimated with the maximum-likelihood method with Amos software (Arbuckle, 1999).

\section{Results}

\section{Descriptive and correlational analyses}

Table 1 shows means, standard deviations, Cronbach's alpha reliabilities, and correlation coefficients for the study variables. There were significant positive correlations between Neuroticism-Anxiety, and Aggression-Hostility with Rejection, and Sociability with Emotional Warmth, whereas there was a significant negative correlation between Aggression-Hostility with Emotional Warmth. Job Demand was positively related with Emotional Warmth. Alpha reliabilities were acceptable, from .67 to .87 .

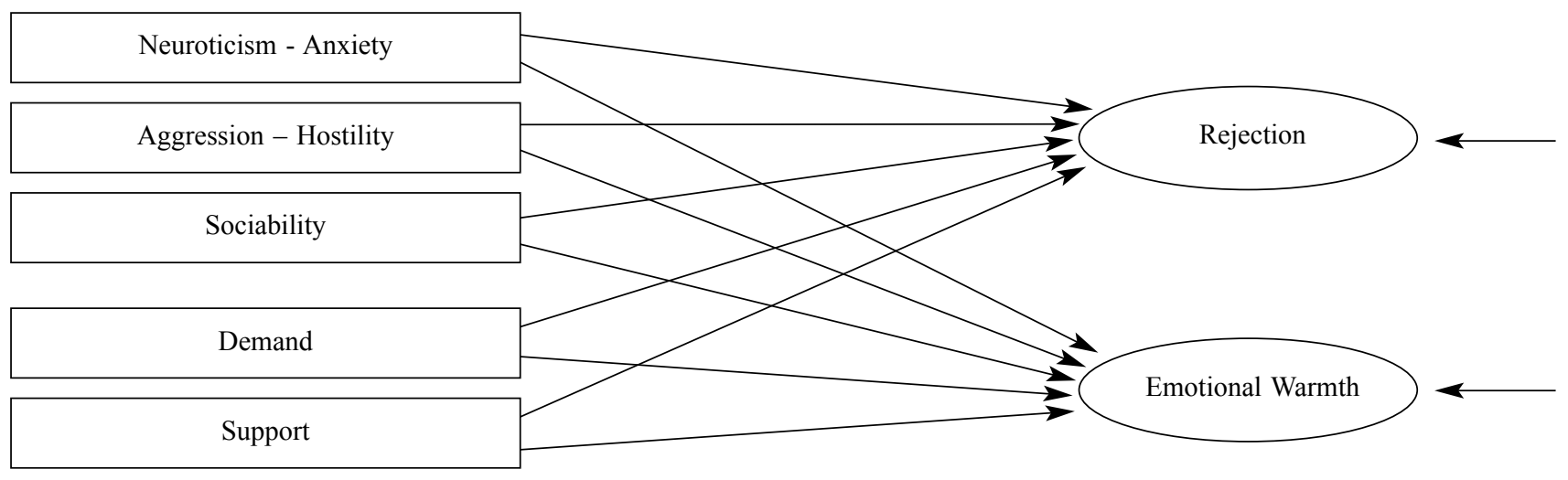

Figure 2. Personality and job variables for the prediction of parenting practices (R: Rejection; EW: Emotional Warmth).

Table 1

Correlation coefficients, alpha reliabilities and descriptive statistics of study variables

\begin{tabular}{|c|c|c|c|c|c|c|c|}
\hline Variable & 1 & 2 & 3 & 4 & 5 & 6 & 7 \\
\hline 1. Neuroticism-Anxiety & .81 & & & & & & \\
\hline 2. Aggression-Hostility & $.42 * * *$ & .76 & & & & & \\
\hline 3. Sociability & $-.14^{*}$ & .00 & .73 & & & & \\
\hline 4. Demand & $.12 *$ & .10 & -.05 & .70 & & & \\
\hline 5. Support & -.04 & -.08 & -.03 & -.09 & .87 & & \\
\hline 6. Rejection & $.15^{* *}$ & $.21 * * *$ & -.10 & .10 & -.05 & .67 & \\
\hline 7. Emotional Warmth & -.10 & $-.12 *$ & $.22 * * *$ & $.12 *$ & .07 & $-.29 * * *$ & .70 \\
\hline $\mathrm{M}$ & 6.36 & 5.06 & 6.46 & 8.06 & 26.18 & 9.18 & 21.14 \\
\hline SD & 3.92 & 3.13 & 2.98 & 3.39 & 7.93 & 1.90 & 2.46 \\
\hline
\end{tabular}

Alpha reliabilities are shown in the main diagonal.

${ }^{*} p<0.05 ; * *<0.01 ; * * p<0.001$. 


\section{Structural equation modeling analyses}

The first half in Table 2 shows standardized parameter estimates for three structural equation models: personality, job, and mixed models (see Figure 2). In the personality model, Aggression-Hostility and Sociability had a significant effect on Rejection $(.23,-.14$, respectively), and Emotional Warmth $(-.14, .19$, respectively). In the job model there was only a significant effect of Job Demand on Emotional Warmth (.14, $p<.05$ ). Equivalent effects were also observed in the mixed model, when all parameters were freely estimated.

Model fit is shown in the second half of Table 2. Despite the slight variations between estimated parameters in the three models, chi-square tests showed significant differences between the personality and job models $\left(\Delta \chi^{2}[2]=210.75\right.$ $-196.53=14.22, p<.001)$, the job and mixed model $\left(\Delta \chi^{2}\right.$ $[6]=210.75-183.29=27.46, p<.001)$, and in a lesser extent between the personality and mixed models $\left(\Delta \chi^{2}[4]\right.$ $=196.53-183.29=13.24, p<.01)$. These outcomes indicate that the mixed model was the best available representation of observed data, with acceptable additional fit indices (GFI $=.95, \mathrm{CFI}=.93$; TLI $=.91$, RMSEA $=.04)$. The explained variance of each dependent variable was the highest in the mixed model, with coefficients of determination of .08 and .10 for Rejection and Emotional Warmth, respectively.

Partial support was evident for the first hypothesis because only Aggression-Hostility was positively related to Rejection, whereas the second hypothesis was fully supported as Sociability was positively related with Emotional Warmth. In addition, no support was found for our third hypothesis because Job Demand was not related with Rejection but with Emotional Warmth. The fourth hypotheses received full support as the mixed model provided the best adjustment to data.

\section{Discussion}

This study was designed to compare the contribution of personality and job variables to the prediction of parental rearing practices. The results supported a mixed model were job and personality variables added significantly to the explained variance in parenting. In this model, AggressionHostility and Sociability were significant predictors of Rejection and Emotional Warmth, whereas Job Demand was a significant predictor of Emotional Warmth.

The significant positive direct effect of Job Demand on Emotional Warmth was an unexpected outcome. This finding was contrary to our hypothesis and past research demonstrating that stressed parents reported using more authoritarian, power assertive discipline strategies with offspring (Crouter \& Bumpus, 2001; Repetti, 1994). Considering that a high work load does not necessarily imply to be stressed by one's job, an explanation of this outcome could be that parents with more psychological demands at work might attempt to exert an affectionate and loving attitude towards children perhaps as a coping strategy. Another explanation of this finding could be that people who self-select into demanding jobs may also have more psychological resources that could enhance the ability to balance work and home demands. Moreover, parents with more demanding jobs might have a greater income and face fewer income-related stressors, which might exert a positive influence in parent - child interactions by reducing the exposition to demographic risk and its likely negative influence on parenting (Kochanska et al., 2007).

The virtually equivalent magnitude effects but with different signs of Aggression-Hostility and Sociability on both parenting styles was an interesting outcome. AggressionHostility and Sociability were significant predictors of

Table 2

Standardized Parameter Estimates and Fit Indices

\begin{tabular}{|c|c|c|c|c|c|c|}
\hline & \multicolumn{2}{|c|}{ Personality Model } & \multicolumn{2}{|c|}{ Job Model } & \multicolumn{2}{|c|}{ Mixed Model } \\
\hline & Rejection & Emotional Warmth & Rejection & Emotional Warmth & Rejection & Emotional Warmth \\
\hline Neuroticism-Anxiety & -.00 & -.02 & - & - & -.01 & -.03 \\
\hline Aggression-Hostility & $.23 * *$ & $-.14^{*}$ & - & - & $.22 * *$ & $-.14^{*}$ \\
\hline Sociability & $-.14^{*}$ & $.19 * *$ & - & - & $-.14^{*}$ & $.20 * *$ \\
\hline Demand & - & - & .09 & .14 & .07 & $.16^{* *}$ \\
\hline Support & - & - & -.09 & .08 & -.08 & .08 \\
\hline$R^{2}$ & .07 & .06 & .02 & .03 & .08 & .10 \\
\hline$\chi^{2}$ & \multicolumn{2}{|c|}{$196.53 * * *$} & \multicolumn{2}{|c|}{$210.75^{* * *}$} & \multicolumn{2}{|c|}{$183.29 * * *$} \\
\hline df & \multicolumn{2}{|c|}{128} & \multicolumn{2}{|c|}{130} & \multicolumn{2}{|r|}{124} \\
\hline GFI & \multicolumn{2}{|r|}{.94} & \multicolumn{2}{|c|}{.94} & \multicolumn{2}{|r|}{.95} \\
\hline CFI & \multicolumn{2}{|r|}{.92} & \multicolumn{2}{|r|}{.90} & \multicolumn{2}{|r|}{.93} \\
\hline TLI & \multicolumn{2}{|r|}{.90} & \multicolumn{2}{|r|}{.88} & \multicolumn{2}{|r|}{.91} \\
\hline RMSEA & \multicolumn{2}{|r|}{.04} & \multicolumn{2}{|r|}{.04} & \multicolumn{2}{|r|}{.04} \\
\hline
\end{tabular}

Note.

$* p<.05 ; * * p<.01 ; * * *<<.001$; Empty cells indicate parameters set to zero. 
Rejection and Emotional Warmth in either direction at equivalent magnitudes. These outcomes suggest that parents with higher levels of Aggression-Hostility reported higher levels of rejection parenting style, whereas parents with higher levels of Sociability were more likely to inform about caring attitudes towards their children. These results substantiate those found by Peterson et al. (1997), considering that both personality dimensions would be inversely related. Belsky et al. (1995) also reported significant positive correlations between extraversion and parenting styles characterized by positive affect, sensitivity, and cognitive stimulation. The non-significant effect of Neuroticism on Rejection was an unexpected finding and contrary to that found in past research, which might be perhaps attributable to the conceptualization and measurement of parenting. While the current study relied on a self-report measure of parenting, the studies reporting significant associations between neuroticism and negative parenting measured parenting from naturalistic and videotaped observations (Belsky et al., 1995, Clark et al., 2000; Kochanska et al., 2007). Furthermore, parents with higher levels of Neuroticism might perceive their behavior differently than outside observers, and might be less aware of their negative parenting behaviors. These issues should be further explored in future research, perhaps comparing different types of parenting measures.

\section{Limitations and practical implications}

The cross-sectional design of the present study does not allow for a consistent conclusion about the direction of causality between the variables being analyzed. For instance, another plausible interpretation could be that parents with a particular parenting style could be more prone to display aggressive or sociable behaviors. Moreover, only three work characteristics were considered, even though there could be other job related variables that might be significantly associated with parent rearing styles. Work stress and burnout may cause states of chronic anxiety or depression, and increase the likelihood to behave in a hostile and irritable way (Jayaratne, Chess, \& Kunkel, 1986). The focus of the current study was the comparison of direct effects between contextual job variables and personality dimensions. Job strain related outcomes such as depression, anxiety, or burnout, might perhaps be more closely related to parenting practices than purely situational variables. This could be one of the reasons for the lack of association of the job support variable with none of the parenting variables.

Furthermore, it has been shown that there are substantial gender differences in personality traits concerning parenting (Belsky et al., 1995), job stress antecedents and outcomes (Jansen, Kant, Kristensen, \& Nijhuis, 2003), and the effect of work circumstances on parenting behaviours (Costigan et al., 2003). However, it has also been reported that similarities in parenting stress for mothers and fathers were more common than differences (Deater-Deckard, \& Scarr, 1996; Kacynski et al., 2006). In this study, we found that there were no significant differences between males and females in the hypothesized relationships, therefore, these results have not been reported.

The study of the interrelationships of work and family has become an important area of enquiry in family research due to the increasing permeability between these two important realms. The findings in the present study indicate that a model where personality and job situational variables were considered as antecedent variables of parenting was the best representation of the observed data, although personality dimensions explained a higher proportion of variance in observed parenting than situational job characteristics. Obviously, there are meaningful links between psychosocial working conditions, individual dispositions and family interactions that might impact specific parenting behaviors. The comparison of the direct effects of work and personality on parenting behavior, suggests that whereas job demand and support might influence upbringing practices, personality dimensions such as Aggression-Hostility and Sociability could play a key and symmetrical role on antagonistic parenting styles such as Rejection and Emotional Warmth. The relationships between the family and work realms are intricate, thus, future and more complex research designs are needed to disentangle the connections between them.

\section{References}

Abidin, R. R. (1992). The determinants of parenting behavior. Journal of Clinical Child \& Adolescent Psychology, 21, 407412. doi:10.1207/s15374424jccp2104_12

Allen, T. D., Herst, D. E. L., Bruck, C. S., \& Sutton, M. (2000). Consequences associated with work-to-family conflict: A review and agenda for future research. Journal of Occupational Health Psychology, 5, 278-308. doi:10.1037/1076-8998.5.2.278

Aluja, A., García, O., \& García, L. (2003). Psychometric properties of the Zuckerman-Kuhlman personality questionnaire (ZKPQ-III-R): A study of a shortened form. Personality and Individual Differences, 34, 1083-1097. doi:10.1016/S0191-8869(02)00097-1

Arbuckle, J. L. (1999). AMOS 4 [Computer software] Chicago, IL: SmallWaters Corporation.

Arrindell, W. A., Akkerman, A., Bages, N., Feldman, L., Caballo, V. E., Oei, T. P. S.,... Zaldívar, F. (2005). The short-EMBU in Australia, Spain, and Venezuela. European Journal of Psychological Assesment, 21, 56-66. doi:10.1027/1015-5759.21.1.56

Barnett, R. C., Gareis, K. C., \& Brennan, R. T. (1999). Fit as a mediator of the relationship between work hours and burnout. Journal of Occupational Health Psychology, 4, 307-317. doi:10.1037/1076-8998.4.4.307

Baumrind, D. (1971). Current patterns of parental authority. Developmental Psychology Monographs, 4, 1-103. doi:10.1037/ h0030372 
Belsky, J. (1984). The determinants of parenting: A process model. Child Development, 55, 83-96. doi:10.1111/j.1467-8624. 1984.tb00275.x

Belsky, J., Crnic, K., \& Woodworth, S. (1995). Personality and parenting: Exploring the mediating role of transient mood and daily hassles. Journal of Personality, 63, 905-929. doi:10.1111/j.1467-6494.1995.tb00320.x

Belsky, J., Gilstrap, B., \& Rovine, M. (1984). Stability and change in mother-infant and father-infant interaction in a setting study. Child Development, 55, 692-705. doi:10.1111/j.14678624.1984.tb03808.x

Blanch, A., \& Aluja, A. (2009).Work, family and personality: A study of work-family conflict. Personality and Individual Differences, 46, 520-524. doi:10.1016/j.paid.2008.12.004

Bollen, K. A. (1989). Structural equations with latent variables. New York, NY: John Wiley \& Sons, Inc.

Browne, M. W., \& Cudeck, R. (1993). Alternative ways of assessing model fit. In K. A. Bollen \& J. S. Long (Eds.), Testing structural equations models (pp. 136-162). Newbury Park, CA: Sage.

Castro, J., de Pablo, J., Gómez, J., Arrindell, W. A., \& Toro, J. (1997). Assessing rearing behavior from the perspective of the parents: A new form of the EMBU. Social Psychiatry and Psychiatric Epidemiology, 32, 230-235. doi:10.1007/BF00788243

Clark, L. A., Kochanska, G., \& Ready, R. (2000). Mother's personality and its interaction with child temperament as predictors of parenting behavior. Journal of Personality and Social Psychology, 79, 274-285. doi:10.1037/0022-3514. 79.2.274

Costigan, C. L., Cox, M. J., \& Cauce, A. M. (2003). Work-parenting linkages among dual-earner couples at the transition to parenthood. Journal of Family Psychology, 17, 397-408. doi:10.1037/0893-3200.17.3.397

Crouter, A. C., \& Bumpus, M. F. (2001). Linking parents' work stress to children's and adolescents' psychological adjustment. Current Directions in Psychological Science, 10, 156-159. doi:10.1111/1467-8721.00138

Deater-Deckard, K., \& Scarr, S. (1996). Parenting stress among dual-earner mothers and fathers: Are there gender differences? Journal of Family Psychology, 10, 45-59. doi:10.1037/08933200.10.1.45

Enns, M. W., Cox, B. J., \& Larsen, D. K. (2000). Perceptions of parental bonding and symptom severity in adults with depression: Mediation by personality dimensions. Canadian Journal of Psychiatry, 45, 263-268.

García, L. F., Aluja, A., \& del Barrio, V. (2006). Effects of personality, rearing styles and social values on adolescents' socialization process. Personality and Individual Differences, 40, 1671-1682. doi:10.1016/j.paid.2006.01.006

Goodman, S. H., \& Gotlib, I. H. (1999). Risk for psychopathology in the children of depressed parents: A developmental model for understanding mechanism of transmission. Psychological Review, 106, 458-490. doi:10.1037/0033-295X.106.3.458

Hoffman, M. L. (1975). Moral internalization parental power and the nature of parent-child interaction. Developmental Psychology, 11, 228-229. doi:10.1037/h0076463
Houston, B. K., \& Vavak, C. R. (1991). Cynical hostility: developmental factors, psychological correlates, and health behaviors. Health Psychology, 10, 9-17. doi:10.1037/02786133.10.1.9

Hughes, D. L., \& Galinsky, E. (1994). Work experiences and marital interactions: Elaborating the complexity of work. Journal of Organizational Behavior, 15, 423-438. doi:10.1002/job.4030150507

Jansen, N. W. H., Kant, I., Kristensen, T. S., \& Nijhuis, F. J. N. (2003). Antecedents and consequences of work-family conflict: A prospective cohort study. Journal of Occupational and Environmental Medicine, 5, 479-491. doi:10.1097/01.jom. 0000063626.37065.e8

Jarvis, P. A., \& Creasey, G. L. (1991). Parental stress, coping and attachment in families with an 18-month-old infant. Infant Behavior and Development, 14, 383-395. doi:10.1016/01636383(91)90029-R

Jayaratne, S., Chess, W. A., \& Kunkel, D. A. (1986). Burnout: Its impact on child welfare workers and their spouses. Social Work, 31, 53-59.

Kaczynski, K. J., Lindahl, K. M., Malik, N. M., \& Laurenceau, J. P. (2006). Marital conflict, maternal and parental parenting, and child adjustment: A test of mediation and moderation. Journal of Family Psychology, 20, 199-208. doi:10.1037/08933200.20.2.199

Karasek, R. A. (1985). Job Content Questionnaire and user's guide. Los Angeles, CA: University of Southern California.

Karasek, R., Brisson, C., Kawakami, N., Houtman, I., Bongers, P., \& Amick, B. (1998). The Job Content Questionnaire (JCQ): An instrument for internationally comparative assessments of psychosocial job characteristics. Journal of Occupational Health Psychology, 3, 322-355. doi:10.1037/1076-8998.3.4.322

Kinnunen, U., Gerris, J., \& Vermulst, A. (1996). Work experiences and family functioning among employed fathers with children of school age. Family Relations: Journal of Applied Family \& Child Studies, 45, 449-455. doi:10.2307/585175

Kochanska, G., Aksan, N., Penney, S. J., \& Boldt, L. J. (2007). Parental personality as an inner resource that moderates the impact of ecological adversity on parenting. Journal of Personality and Social Psychology, 92, 136-150. doi:10.1037/ 0022-3514.92.1.13

McCrae, R. R., \& Costa, P. T., Jr. (1999). A five-factor theory of personality. In L. A. Pervin \& O. P. John (Eds.), Handbook of personality: Theory and research ( $2^{\text {nd }}$ ed., pp. 139-153). New York, NY: Guilford Press.

Morris, J. E., \& Coley, R. L. (2004). Maternal, family, and work correlates of role strain in low-income mothers. Journal of Family Psychology, 18, 424-432. doi:10.1037/0893-3200.18.3.424

NICHD Early Child Care Research Network. (2004). Fathers' and mothers' parenting behavior and beliefs as predictors of children's social adjustment in the transition to school. Journal of Family Psychology, 18, 628-638. doi:10.1037/0893-3200.18.4.628

Patterson, G. (1983). Stress: A change agent for family process. In N. Garmezy \& M. Rutter (Eds.), Stress, coping, and development in children (pp. 235-264). New York, NY: McGraw-Hill. 
Pedersen, W. (1994). Parental relations, mental health, and delinquency in adolescents. Adolescence, 29, 975-990.

Peterson, B. E., Smirles, K. A., \& Wentworth, P. A. (1997). Generativity and authoritarianism: Implications for personality, political involvement, and parenting. Journal of Personality and Social Psychology, 72, 1202-1216. doi:10.1037/00223514.72.5.1202

Repetti, R. L., (1989). Effects of daily workload on subsequent behavior during marital interaction: The roles of social withdrawal and spouse support. Journal of Personality and Social Psychology, 57, 651-659. doi:10.1037/0022-3514.57.4.651

Repetti, R. L. (1994). Short-term and long-term processes linking job stressors to father - child interaction. Social Development, 3, 1-15. doi:10.1111/j.1467-9507.1994.tb00020.x

Repetti, R. L., \& Wood, J. (1997). Effects of daily stress at work on mothers' interactions with preschoolers. Journal of Family Psychology, 11, 90-108. doi:10.1037/0893-3200.11.1.90

Story, L. B., \& Repetti, R. (2006). Daily occupational stressors and marital behavior. Journal of Family Psychology, 20, 690700. doi:10.1037/0893-3200.20.4.690
Tellegen, A. (1985). Structures of mood and personality and their relevance to assessing anxiety, with an emphasis on self-report. In A. Tuma \& J. Mason (Eds.), Anxiety and the anxiety disorders (pp. 681-706). Hillsdale, NJ: Erlbaum.

Zemore, R., \& Rinholm, J. (1989). Vulnerability to depression as a function of parental rejection and control. Canadian Journal of Behavioural Science, 21, 364-376. doi:10.1037/ h0079844

Zuckerman, M. (2005). Psychobiology of personality. New York, NY: Cambridge University Press.

Zuckerman, M., Kuhlman, M. D., Joireman, J., Teta, P., \& Kraft, M. (1993). A comparison of three structural models for personality: The Big Three, the Big Five, and the Alternative Five. Journal of Personality and Social Psychology, 65, 757768. doi:10.1037/0022-3514.65.4.757

Received October 8, 2010 Revision received December 22, 2010 Accepted January 17, 2011 